ages, and in that way you can build up the nervous gystem so you can cure them of the nervous diseases. If you take the half-grown boys who have ear-aches and who pay attention to their faces to press out the little comedones and imagine they are ill, it is just as important that they should be treated as if they were affected with typhoid fever. You will find each of these boys has a specific. They have a book in their pocket which tells all about the hundred and one thinge they have. It is true the stomach is the cause of a great deal of this dis. ease, for if they get a little wind in the colon, away they go into hysteria. The only way you can cure them is to bring them down to nature, send them out to farms or out here or to the army. But with medicines the patients grow up to be invalids, the kinds the books in the drug-stores tell us about.

Dr. Louis Faugères Brshop, New York City-I think the object of the paper has been fulfilled. I drew attention to this condition. I did not mean to neglect these girls by using "he" but 1 meant that to cover the whole race.

\section{TETANY IN INFANCY; WITH A REPORT OF SIX CASES.}

Presented to the Section on Diseases of Children, at the Forty-ninth Annual Meeting of the American Medical Association, held at Denver, Colo., June 7-10, 1898.

BY JOHN LOVETT MORSE, A.M., M.D.

Physician to Out-Patients at the City Hospital and at the Infants Hospital, Boston; Assistant in Clinical Medicine, Harvard Medical School. Boston. Mass.

Very great differences of opinion exist with regard to what constitutes tetany, as well as to the frequency of its occurrence and its etiology and pathology.

It is generally accepted that the most characteristic symptom of tetany is muscular rigidity, this rigidity occurring as intermittent paroxysmal contractures. The duration and intensity of the contractures vary, in some cases being long and remittent, in others fleeting and occurring at long intervals. The extent of the contractures also varies within wide limits, the seat par excellence, however, being in the muscles of the arms, especially of the fore-arms. The positions assumed by the hands and feet during these contractures are very characteristic. The fingers are flexed at the metacarpo-phalangeal joints, while the phalan. ges are extended. The thumb is strongly adducted in the extended position. The wrist is acutely flexed and the hand turned to the ulnar side. The elbowand shoulder-joints are not involved in the milder cases. The feet are strongly extended, sometimes in the position of pure equinus, but more often in that of equino-varus. The first phalanges of the toes are strongly flexed, the others extended. The knee- and hip-joints are usually free. Opisthotonos is not very uncommon in the severe cases. Associated with the contractures are other symptoms, some or all of which are present in every case. These are: Increased electric excitability of both nerve and muscle to faradism and galvanism, with changes in the qualitative reaction to galvanism. This is often known as Erb's symptom and is probably the most constant. Increased mechanical excitability of both nerve and muscle. Special examples of this are the occurrence of characteristic contractures as the result of pressure on the large nerve trunks and arteries, "Trousseau's symptom," and spasm of the facial muscles when the skin over the trunk of the facial nerve is irritated or the nerve is struck a sharp blow, "Chvostek's symptom" or the "facialis phenomenon." Laryngospasm. Convalsions. Sensory disturbances, including pain on motion and during spasms, as well as many others impossible to determine in infants. Vasomotor and trophic disturbances, the most characteristic being edema of the wrists and ankles. Fever, which is inconstant and intermittent. The intelligence is always unimpaired, even during the paroxysmal contractures. All agree that the presence of the peculiar paroxysmal contractures justifies the diagnosis of tetany. There is great difference of opinion, however, as to whether the presence of one or more of the other symptoms without contractures justifies the diagnosis. It is to this condition that the term "latent tetany" is applied. Even here, however, there is no consensus of opinion, some apparently limiting the term to the condition in which irritation of the muscle or nerve brings on contractures which are otherwise absent, while others consider the presence of even one symptom as pathognomonic and sufficient for the diagnosis. As a rule, those who recognize the existence of latent tetany consider it the same as tetany, differing from the latter only in degree. If these symptoms are to be considered as pathognomonic and sufficient for the diagnosis of tetany, whether the characteristic contractures are present or not, they should be always present where there are contractures and should never occur in other conditions. Trousseau's symptom and the facial phenomenon are sometimes absent, and often only temporarily present when there are typic contructures. Moreover, Trousseau's symptom is often met with in hysteria, while the facial phenomenon is found in many other conditions, as epilepsy, hysteria, phthisis and nourasthenia. Laryngospasm is frequent in tetany, but not constant, and is often seen in children who have no other symptoms of tetany. Convulsions and disturbances of sensation, as well as vasomotor and trophic disturbances, occur in many other diseases. It is evident, therefore, that these three symptoms--laryngospasm, Trousseau's symptom and the facial phenomenon-are not constant in cases which show the typic contractures of tetany, and that they occur in many conditions in which there is no question of tetany. Hence they can not be considered as pathognomonic of tetany, and do not, either singly or in combination, afford sufficient ground for the diagnosis either of tetany or latent tetany. They must be regarded merely as particular instances of increased mechanical or reflex excitability which may be the result of a very great variety of causes and pathologic conditions. The only pathognomonic symptom of tetany, therefore, is spontaneous, intermittent, paroxysmal muscular contracture. The term "tetany" should be applied only to those cases in which this symptom is present, and no cases of increased reflex excitability in which this symptom does not occur should be regarded as examples of the disease. The term "latent tetany," is therefore a misnomer and should be dropped.

\section{ETIOLOGY.}

Numerous theories as to the etiology of tetany have been advanced, and have found vigorous defenders and opponents. The question is still unsettled, however, probably partly on account of the differences of opinion as to what constitutes tetany, and partly on account of the inherent diffioulties of the subject. The theory of the older authors that it is of rheumatic origin has long been given up. The position that it is merely a manifestation of hysteria must also be regarded as untenable. The theory that it is cerebral in origin was founded on an erroneous conception 
of the disease, and is no longer accepted. The theory that it is a variety of acute anterior poliom yelitis can not easily be set aside, however, as certain quite definite lesions have been found in the anterior horns. As the cases of tetany which do notdie of some intercurrent disease nearly always recover, these lesions must, as a rule, be transitory. They may very probably be frequently due to the action of toxic substances in the circulation, the result of diseased conditions elsewhere.

The most ardent and extreme advocate of the rachitic theory is undoubtedly Kassowitz. His line of argument is somewhat as follows: Craniotabes is a lesion of rickets. Craniotabes may be represented only by meningeal hyperemia, and hence be incapable of demonstration. Laryngospasm is due to craniotabes. Laryngospasm is a symptom of rickets. Other symptoms of increased neuro-muscular excitability are seen in rickets. They are of the same nature as laryngospasm and hence due to the same cause. Laryngospasm and other nervous manifestations are symptoms of tetany; in fact, they are tetany. Hence tetany is a symptom of rickets.

There are many obvious objections to this reasoning. It is not proven that craniotabes is the cause of laryngospasm, or that meningeal hyperemia produces the same results as craniotabes. Moreover, laryngospasen occurs in tetany when there is no evidence of rickets, in rickets when there are no other evidences of tetany, and alone when there are no evidences of either tetany or rickets.

Although not agreeing with the extreme views of Kassowitz, most of the German and Austrian authorities have accepted the rachitic theory in a more or less modified form. Some of the arguments in favor of this view are, that almost all cases of tetany show evidences of rickets, that they are both more frequent in winter, and that they occur in children of the same age. Some of the arguments against it are, that very many cases of other diseases than tetany show evi. dences of rickets, that the symptoms of increased neuro-muscular excitability, with the exception of laryngospasm, are rare among rachitics, and that tetany is more likely to occur in mild than in severe cases of rickets. The fact that rickets is common all the year round, although much more so in the winter, while tetany very rarely occurs in the summer, would seem to point to some common cause for both conditions which is active only in the winter. This cause is most probably the indoor life of the winter, with its lack of sunlight and oxygen and its exposure to noxious vapors. These furnish the opportunity for the formation of respiratory toxins which may produce changes in the circulation that lead to malnutrition of various tissues with subsequent symptoms.

Several theories locating the origin of tetany in the gastro-intestinal canal have been advanced. These have received their main support from the French authorities. The dehydration and reflex theories need be mentioned only to be set aside. That of autointoxication, however, is worthy of careful consideration. The friends of this theory say that tetany is almost always associated with diarrhea or other digestive disturbances. They say that the reason that all children suffering from indigestion do not have tetany is that some peculiar chemic combination is necessary, or because their nervous system is insusceptible. When tetany occurs in infants who present no symp. toms of indigestion, they assume that the nervous system is easily affected, or that this peculiar chemic combination may be produced without causing other symptoms. They also state that when the digestive disturbances are relieved the tetany ceases. They attribute the frequency of tetany in rachitis to the gastro-enteric disturbances of this disease. The opponents of this theory say that gastro-enteric disorders are very common and tetany very rare; that digestive disturbances are more common in summer and tetany in winter; and that the only basis for the assumption of peculiar susceptibility or special chemic combinations is in the imaginations of the originators.

The most recent, and perhaps the most plausible, theory assumes that there is no single pathologic cause for tetany, but that, like epilepsy, it may arise from many causes. Like epilepsy, too, it must be regarded merely as a nosologic entity, and not as a definite disease. In improper hygienic surroundings, in rickets, in gastro-intestinal disorders, in acute disease, and in various intoxications are present conditions capable of causing the formation of various toxic substances. The action of all these poisonous substances may show itself by a special modification, rather functional than organic, of the central or peripheral nervous system. The various lesions of the nervous system found in tetany are not inconsistent with this conception.

\section{MORBID ANATOMY.}

The lesions which bave been found in the nervous system in tetany are very variable. Tonnellé, Blondeau, Grisolle, Trousseau and Bouchut have found hyperemia of various portions of the brain and cord and their meninges; Weiss, Bonome, Cervesato and Sarbo various degrees of poliomyelitis of the cervical enlargement; Stasse, Niemayer and Schultze peripheral neuritis; and Loos, Berger and others no lesions. The most characteristic lesions, however, are probably those in the cells of the anterior horns in the cervical enlargement. These vary in degree from hyperemia and swelling to atrophy and sclerosis, the severity of the process probably depending on the duration and intensity of the disease. It is probable that certain lesions in this region are present in all cases, but that in recent ones they are too superficial to be recognized. Whether they are primary here or secondary to an ascending neuritis is at present entirely undetermined. As they have not been found constantly, however, further verification is necessary before they can be accepted as the essential lesions of the disease. Nevertheless, they do correspond more closely to the symptoms of the disease than any other lesions which have been described, and seem at any rate to afford a fairly satisfactory explanation for them.

The frequency of tetany must naturally depend on the definition of the disease which is accopted. If the presence of symptoms of increased neuromuscular excitability is considered as evidence of latent tetany, and latent tetany is classed as tetany, the disease will be frequently encountered. If, however, only those cases in which the typic paroxysmal contractures are present are regarded as tetany it will be seen much less often. This difference in classification undoubtedly explains to a great extent the much greater frequency of the disease in Germany and Austria than in France and Italy. It does not 
entirely account for the discrepancy, however, and there is probably but little doubt that tetany, even in the strict interpretation of the term, is much more common in the first-named countries. It is still less common in this country, being, indeed, something of a rarity. Griffith, in addition to five cases of his own, was able to find but seventy-two cases reported in American literature up to 1894 , although he included in his list a number of cases of muscular spasm, which, strictly speaking can not be accopted as cases of tetany. In a careful review of American medical literature from Jan. 1, 1894, to Jan. 1, 1898, I am able to find but thirteen additional cases. They are, in brief, as follows:

1. Lewi: Nine months. Constant, typic spasm in hands. Arms and lege painful. One convulsion. Spasm became remittent, then ceased. Duration, three weeks. Neurotic family history. Rachitic. No craniotabes. No gastro-intestinal disturbances.

2. Lewi : Eight months. Typic, intermittent spasms in hands and feet, lasting hours or days. Hande and feet tender and painful. Increased electric reaction. Duration, six weeks. Recurrent attack two months later with death in convulsion. An older child had had disease. Rachitic. No craniotabes. Gastro-intestinal disturbance always. Constipation during attack.

3. Lewi : Eight months. 'Typic, continuous spasm in hands and feet. Hands and feet swollen, tender and painful. Increased electric reaction. Duration, two weeks. Rachitic No craniotabes. Vomiting. Constipation.

4. Lewi : Thirteen months. Remittent spasm in hands and feet, most in hands. Hands and feet swollen, tender and painful. Laryngismus stridulus. Duration, two weeks. An older child had had disease. Markedly rachitic. No craniotabes. Vomiting. Constipation.

5. Crandall: Six months. Began with peculiar attacks of staring. In a month well-marked and ty pic paroxysms, involv ing neck and all extremities, lasting one and $a$ half to two hours. Five to eight attacks in twenty-four hours. No laryngismus stridulus. Duration, eight weeks. Moderately rachitic. No craniotabes. Poor breast feeding. Diarrhea, later constipation. Phimosis. Correction of phimosis had no effect. Complete recovery in eleven days after correction of diet and relief of constipation.

6. Crandall: Eleven months. Twelve to twenty-four attacks of laryngismus stridulus and convulsions in twenty-four hours. Duration, two minutes. Spasms fairly typic. Duration, three weeks. Markedly rachitic. No craniotabes. Breast and general diet. Vomiting. Alternate diarrhea and constipation. Recovery in two days after correction of diet and cathartic.

7. Preston: Three and a half years. Typic spasms in arms, less so in legs, lasting a few minutes; intervals of months or ten to fifteen in twenty.four hours. No pain. Trousseau' eymptom present. Began at one year. Duration unknown.

8. Krauss : Six months. Typic paroxysms; continuous for two weeks at height of attack. Much pain. Swelling of face and extremities. Trousseau's symptom present. Duration five weeks. No note as to rickets. Artificial food. Constipation, then diarrhea. Dentition.

9. Krauss: Eighteen months. Mild attacks, lasting a few minutes, at intervals of half an hour to two hours. Duration one week. No note as to rachitis. Vomiting. Diarrhea. Bronchitis.

10. Krauss: Thirteen months. Mild attacks, lasting five to ten minutes, several times, daily. Duration, sixteen days. No note as to rachitis. Gastro-intestinal disturbance. Bron chitis.

11. Krauss: Nine months. Paroxysms, involving hands and legs. Duration, three weeks. No note as to rachitis. Bronchitis.

12. Krauss: Eleven months. Remittent paroxysms; most severe in arms. Duration, two weeks. No note as to rachitis Severe gastro-intestinal disturbance. Dentition. Bronchitis.

13. Carpenter: Eleven months, Tonic spasms. Laryn gismus stridulus. Recovery, slow. Mild recurrence for several years. No note as to rachitis. Followed purulent effusion in shoulder-joint after scarlet fever.

A case reported by Miles as tetany, and another by Carpenter, are probably cases of tetanus. In another, reported by Carpenter, the diagnosis was based entirely on laryngismus stridulus, and, therefore, can not be accepted.
The disease is certainly a very unusual one in Boston, as is shown by the following statistics from the Medical Out-Patient Department of the Infants' Hospital, during the last two years. The great majority of the patients treated there are infants under two years of age, belonging to the poorest classes. Both their age and hygienic surroundings would seem likely, therefore, to render them especially favorable subjects for the development of both rickets and tetany. Seventy-one hundred and fourteen cases of disease were treated during the years 1896 and 1897 , and among them was one case of tetany. One hundred and ninety-six were classified as rickets. This number, however, comprises only those cases in which rachitis was the condition demanding treatment, and does not include the far greater number of cases in which rickets was present as a complication. The one case of tetany, which is reported in full below, showed but few evidences of rickets. It would seem from these figures, therefore, that rachitis is not a factor of great importance in the etiology of tetany. I have, during the last five years, seen six cases of tetany in infants. Three were mild and three severe. The thistories of these are as follows:

Case 1.-Annie P., four months old ; was seen at the Mass. achusetts Charitable Eye and Ear Infirmary on account of a suspicious eruption. The mastoid disease, for which an operation had been performed some days before, was progressing favorably. Nothing was known as to her history, and the contractures had not been noted. There was slight diarrhea and the temperature was moderately elevated. Handling was somewhat painful. There were frequent, short, typic paroxysmal contractures of the hands and arms. No laryngospasm; facial phenomena absent; Trousseau's symptom easily elicited; knee-jerks exaggerated. There were no evidences of rickets. She unfortunately soon passed out of observation, and nothing is known as to the further progress of the case.

Case 2.-Gladys R., colored, four months old, was brought to the Infants' Hospital chiefly because she did not gain weight. She had always been feeble, and was said to weigh less than at birth. She had been fed on a varied collection of patent "foods," the mixture at the time being one of Mellins" Food and boiled milk. She had all of this mixture which ghe would take at any time. There was no vomiting, some ab. dominal pain, and a moderate diarrhea. She had "spasms" frequently, in which she "wriggled and clenched her hands." No laryngospasm. She was poorly developed, but fairly nour. ished. There was no evidence of rickets. During the examination there were frequent short, intermittent, typic contractures in the arms and hands. There was apparently no pain, either on handling or during the paroxysms. The facial phenomenon could not be obtained, but Trousseau's symptom was easily elicited. She was given a carefully modified milk, but no drugs. When seen, eight days later, she had gained ten ounces, and the gastro.intestinal symptoms had diminished greatly. There had been no spasms for some days. Trous. seau's symptom, however, was easily developed. She was then lost sight of, and nothing is known as to the final outcome of the case.

Case 3.-Rebecca B., ten months old, was brought to the Infants' Hospital, May 6. Since the first of January she had had one or more "spasms" a day, lasting from a few seconds to five minutes. They also sometimes occurred during sleep. In these "spasms" the upper part of the body stiffened, the arms were flexed at the elbows, the thumb contracted into the palm, and she "got black in the face." For the same length of time she had had frequent attacks of noisy breathing. An older child had had a similar trouble, lasting a month at one time. She was fed on breast milk and on a mixture of cow's milk and water. She seldom vomited, and the dejections were normal, except for an occasional curd. Her surroundings were very good for a child of the poorer classes. She was well developed and nourished. Color good. Skin normal. Anterior fontanelle, six c.c. by eight c.c. No craniotabes. Two teeth. Spine normal. Heart and lungs normal. A considerable rosary. Flaring of lower chest. Abdomen large. Spleen palpable. Epiphyses at wrists enlarged. During the examination she had a typic contracture, involving the arms only, lasting about half a minute. She also had several attacks of laryngospasm. The facial phenomenon was easily elicited, but Trousseau's 
symptom could not be produced. The reflexes were normal. She was put on a carefully modified milk in addition to the breast, and given small doses of bromid. The spasms ceased on the 10th and the laryngismus on the 23d. The facial phenomenon was present on the 10th, but had disappeared on the 13th. No $n \in w$ symptoms developed.

Case 4.-James C., six months old, was seen in consultation with Dr. J. L. Ames, Jan. 25, 1898. He was a large, strong baby at birth, but was completely upset by improper feeding during the first six weeks. From that time on his digestion was feeble, although he was carefully and correctly fed. $\mathrm{He}$ did not gain normally, and vomited from time to time. The stools, however, were normal. His care and surroundings were irreproachable. On the 19th day he began to vomit again, but his dejections remained normal. He cried much, and seemed to be in pain. His temperature ranged in the neighborhood of 100 degrees. Slight "clenching of the hands,"-first noted on the 20 th-gradually increased. He had a mild "spasm" on the $23 \mathrm{~d}$. He was cutting several incisor teeth. The urine was diminished in amount. He was fairly developed and nour. ished. Skin in good condition; rather pale. Fontanelle level - not tense. One tooth; gum distended by another. Slight stomatitis. No rosary. Heart, lungs and abdomen normal. Moderate umbilical hernia. Phimosis. No rigidity of neck, but tendency to hold head backward. Remittent contractures of hands and feet, apparently not attended by pain. Extended thumbs strongly adducted into palms. Little and ring fingers flexed at metacarpo-phalangeal joint, extended at phalangeal ; other fingers firmly flexed. Slight flexion at wrists. Elbow and shoulder joints free. Feet in perfectly typic position. Toes sharply flexed at metatarso-phalangeal joint, extended at phalangeal. Foot much arched and extended. Knees and hips flexed. Reduction of spasm not painful. Facial phenomenon doubtful. Trousseau's symptom easily elicited. Kneejerks lively.

He was given a different modification of milk, calomel, salol and bromid. The further treatment was on these same lines. $\mathrm{He}$ had numerous spasms during the next few days and the paroxysmal contractures increased in severity. Under careful feeding all the symptoms of indigestion disappeared during the next month, but there was no gain in weight. After the first week the contractures diminished rapidly in frequency and severity and were entirely gone in a month.

Case 5.- John W., four months old, was brought to the City Hospital, Oct. 21, 1897. There was no specific history, and the other children were in every way normal. He was born at full term, after a rapid, normal, vertex labor. Convulsions are said to have begun on the day of his birth, and to have continued until some time in July. The mother also states that she noticed contraction of the fingers after the first convulsion, and that it has persisted since. I saw him at the Infants' Hospital in July, however, but noticed no contractures. I sent him to the Summer Hospital at Rainsford Island, with the diagnosis of "starvation." He remained there for some weeks, but no contractures were noted.

He was fed on condensed milk previous to his admission to Rainsford, and on modified milk during his stay there. He was then given Mellins' Food, which he was taking when seen. $\mathrm{He}$ had been vomiting for some weeks. The bowels moved two or three times a day, the dejections being large, yellowish. white and undigested. He slept but little and cried constantly. "The whole body was constantly rigid, the spasm not even relaxing in sleep." Motion was painful.

Poorly developed and emaciated; skin dry; fontanelle level; snuffles; no teeth; mouth normal ; tendency to laryngospasm when crying; unable to hold up head when sitting: when lying, head held backward stiffy, but spasm can be overcome; facial phenomenon not obtained ; heart and lungs normal; no rosary; abdomen large and tense; slight umbilical hernia; no enlargement of liver or apleen ; phimosis ; no glandular enlarge. ment; arms held rigidly flexed at the elbow; shoulders also somewhat rigid; wrists slightly flexed, hands in pronation; extended thumbs very strongly adducted across the palms; fingers flexed at metacarpo-phalangeal and first phalangeal joints, extended at the second. This spasm varied in intensity, but was never voluntarily relaxed. It could be almost entirely overcome, but only with the causation of considerable pain. Trousseau's symptom was not determined because of the constant spasm. There was a teudency to hold the legs crossed, and at times the knees were flexed and the feet extended. The spasm was always very slight, however, and was easily over come; knee-jerks exaggerated; electric reactions and sensa tion not determined.

Warm baths and light rubbing were advised. He was put on a properly modified milk and given small doses of bromid of potassium. Improvement in the digestive symptoms was almost immediate and was soon followed by improvement in the nervoue symptoms. By November 7 the spasms were intermittent, occurring only at intervals, and the arms and legs were used a little voluntarily. Trousseau's symptom was easily elicited. By November 27 the spasms were very infrequent and of slight intensity and all motions were free. All trace of spasm disappeared some woeks later and Trousseau's symptom could not be elicited. There has been no recurrence of the symptoms.

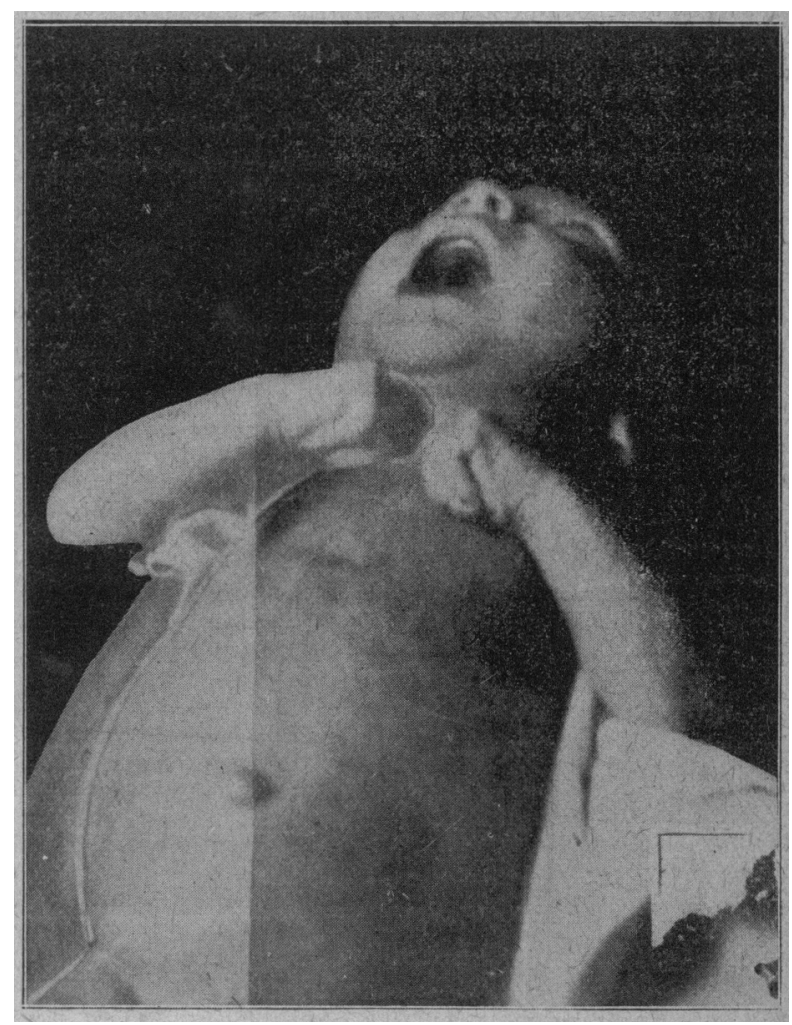

JOHN W

Case 6.-Sherry M., 101\% months old, was seen at the Infants' Hospital June 1, 1897.

Family history: No tuberculosis nor syphilis; father and mother each 29 years of age and well.

First child-Instrumental; nursed ; always well.

Second child-Instrumental ; nursed ; always well.

Third child-Instrumental; nursed only; well up to 11 months, when had an attack of vomiting and diarrhea and began to stiffen. Vomiting, constipation and wasting continued and stiffness increased and continued up to death at 18 months. Had no food but breast and beef-juice.

Fourth child-Instrumental; nursed only; well up to 7 monthe, when had a cough and cold followed by vomiting, constipation, wasting and gradually increasing stiffness ending in death at 11 months. Food was breast, cream and orange juice.

Fifth child-The patient. Normal vertex labor; was well up to 7 months, when it was noted that she was not as active as she had been. Vomiting began and increased, also constipation, which grew steadily worse, the bowels moving only with drugs. At $9 \frac{1}{2}$ months she began to hold her head backward, and for the last three was in much the same condition as when first seen. She had the breast only until her sickness began, but after that was given in addition oatmeal gruel, milk and beef-juice and during the last few days a modified milk. She slept but little, and cried almost constantly. All motion seemed to cause pain and increased and brought on spasm. The spasm was never entirely relaxed even during sleep. Fairly developed and nourished. Skin smooth and sof t. Color fair ; fontanelle normal size; heart, lungs and abdomen normal ; no rosary ; no glandular enlargement; the arms and legs were in a state of almost constant contracture, which never entirely relaxed. Any motion or excitement caused an increase of the spasm with crying. During the more intense spasms the head was much retracted and the back in the position of moderate opisthotonos. Respiratory spasm was marked, the chest being fixed in the position of full inspiration. The arns 
were rigid, their position, however, varying in different attacks. The thumbs were always strongly adducted in full extension. The fingers were flexed at the metacarpo-phalangeal and first phalangeal joints and extended at the second; sometimes extended at the first phalangeal joint also. The lege were held rigidly, the thighs being crossed, the knees extended, the feet slightly extended and the toes flexed. The facial phenomenon was not elicited ; Trousseau's symptom was marked; the knee-jerks were normal. The electric reactions and eensation were not examined.

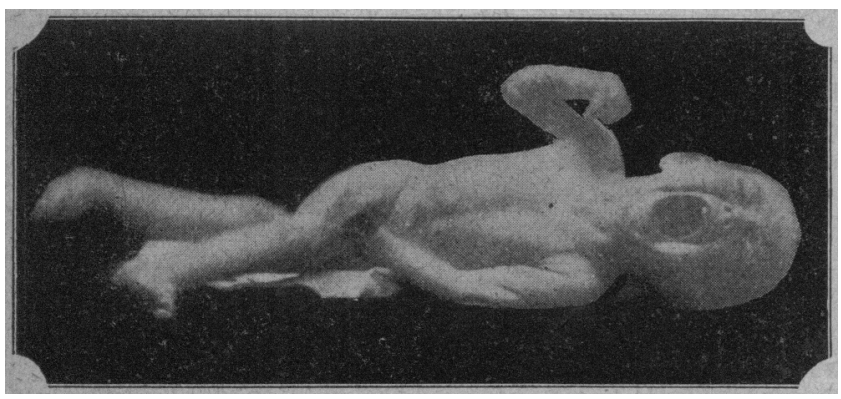

As the history of the other children suggested some trouble with the breast milk, and as this child did better on a mixture of modified milk and breast-milk than on breast-milk alone, the nursing was stopped and she was given modified milk only. She was also given small doses of bromid of potassium. There was no improvement in the spasm, vomiting and constipation. There was also a progressive loss of weight and a continuous temperature, ranging from 99 to 100 degrees. She was therefore sent to the Summer Hospital at Rainsford Island on June 14 and remained there for more than a month. While there she vomited constantly and lost weight steadily. The dejections, however, were normal. Her temperature ranged from 99 to 101 degrees. The contractures continued undiminished. During the next three weeks she improved in every way. She cried less, slept all night and had spasme only when disturbed. The symptoms increased again, however, and ebe was lost sight of until November 22. During this time she was kept on a modified milk of very low percentages, ordered when she was last seen. She had emaciated to a skeleton, and was very weak. She was vomiting a little. The bowels ware constipated but the dejections were normal in character. She slept well and relaxed entirely during sleep. She was quiet when awake but had more or less spasm most of the time. As she was then sixteen montbs old she was given starchy foods in addition to milk. Passive motion and light rubbing were also advised. Improvement from this time on was slow but progressive. The vomiting ceased but the bowels remained somewhat costive. Gain in weight and strength was steady. The spasm diminished slowly, remaining longest in the hands. It left them about March 1, 1898.

\section{TREATMENT.}

It is evident from the obscurity which still exists with regard to the origin and nature of tetany that there can be no specific treatment. As what evidence there is, however, all seems to show that the disease is due to toxic poisoning of some sort, treatment may be directed to the prevention of the formation of toxic substances, and to their elimination, if already formed. It is probable that many of these toxins are absorbed from the alimentary tract and some from the respiratory tract. Others may be produced as the result of abnormal metabolism. The production of alimentary toxins can be best prevented by a suitable diet. Reg. ulation of the diet is probably, therefore, the most important method of preventive treatment. Intestinal antiseptics may also be of use, and are, at any rate, worthy of a trial. The formation and absorption of respiratory toxins can be best prevented by a liberal supply of fresh air and sunlight. Anything which tends to improve the hygienic surroundings is of use. Elimination must naturally take place largely through the intestinal tract, and to a less extent through the kidneys and skin. Emetics, purgatives and lavage of the stomach and colon tend, not only to favor elimination, but also to prevent the absorption of toxic substances already formed. The kidneys must be kept active by a liberal supply of water and possibly by mild diuretics. The skin may be stimulated by proper hygienic measures.

Symptomatic treatment is also important and consists largely in the avoidance of excitants of spasm and in the employment of antispasmodics. Excitants to be avoided are cold, handling, noise and excitement. Antispasmodic treatment may be local, by the use of such measures as warmth, warm baths, inunctions of oil and light massage, or general, by drugs. The bromids and chloral are the most useful, but opium, belladonna, valerian and musk may be tried. During convulsions chloroform or ether may be administered by inhalation.

Blondeau: Quoted by Oddo

Bonome and Cervesato: La Pediatria, 1895, No. 5 and 6; Revue des Mal. de l'Enfance Feb. 1896

Bonchut: Lec. recueilli par Juhel-Rénoy. Paris Méd. 1879, No. 50.

Carpenter: Jovrnal Americ a Medical Association, 1894, 8xiii, p. 182 (assell: Deutsche Med, Woch., 1897, No. 5.

Chrostek: Wien. Med. Presse, 1876.

Comby : La Médecine Infantile, 1894, No. 4

Crandall: Archives of Pedriatics, 1895, xii, 920

Erb: Archiv. f. Phys., iv, 271.

Escherich: Wien. klin. Woch., 1890. No. 40; Berlin klin. Woch., 1897 xxxiv, 861: Traité des Maladies de l'Enfance, Vol. iv, Paris, 1898.

Fischl: Therapeutische Woch., 1896, iii, 973

Frankl-Hochwart: Die Tetanie, Berlin, 1891; Die Tetanie, Spec. Path u. Therap., Nothnagel, Wion., 1897, xi, t 2, ab. 4, 79-207.

Griffith: Am. Journ. Med. Ściences, 1895 , cix, 158

Grisolle: Quoted by Oddo

Hauser: Berlin klin. Woch, 1896, xxxiii, 661, 782

Heubner: Deutsche Med. Woch. 1896, No. 29.9 Kalischer: Revue

Kassowitz: Wien. Med. Woch., 1893, No. 13; Wien. Med. Presse, 1897, Kas.
No. 5.
Kra

Krauss: N. Y. Med. Record, 1896, xlix 44.

Loos: Die Tetanie d. Kind. und ihre Berichtungen zur Laryngospasmus, Leipzig, 1892

News, 1896 lxviii, 36

Niemayer: Quoted by Oddo.

Oddo: Révue de Médecine, 1896, xvi, 458, 572, 667, 749

Orthen: Zeitschr. f. Hyg., 1896, xxii, 1.

Preston: N. Y. Med. Journal, 1895, lхi, 718.

Rehn : Zeitschr. f. Hyg., 1896, xxii, 12

Romme: Gazette Hebdomadaire de Méd., 1897, xliv, 73.

Sarbo: Deutsche Zeitschr. f. Nervenheilk., 1896, viii.

Schultze: Deutsche Med. Woch., 1882, No. 20

Stasse: Quoted by Oddo.

Tonnellé: Gazette Médicale, 1832, iii, No. 1

Tordeus: Jour. de Clin. et de Therap. Infantile, 1897, v, 784.

Trousseau: Cliniques de l'Hotel-Dieu. ii. 207.

Weiss: Samml. Klin. Vorträge, 1881, No. 189.

\section{NEURALGIA AND NERVE CRIES.}

Presented to the Section on Neurology and Medical Jurisprudence, at the Forty-ninth Annual Meeting of the American Medical Association, held at Denver, Colo., June 7-10, 1898.

BY CHAS. HOWARD LODOR, AM., M.D.

CHICAGO, ILL.

From time immemorial certain phases or symptoms of disease which have been uncertain in their pathology or whose pathology has been unknown, have been classified under general terms, vague and uncertain; and these terms have varied with the ages. Time was when the humors of the body accounted for all manifestations of disease which could not be accounted for or classified by the scapel, inspection, or inductive reasoning from the most simple and elementary medical facts. Humors have passed, and we now classify such disturbance as manifestations of a diathesis, or of chronic rheumatism or gout, of the presence in the blood of nerve irritants, as uric acid, toxalbumins, auto-infections, etc., or as due to the cries of sensitive nerves for pabulum which an impoverished circulatory medium no longer furnishes them, and call them neuralgia.

The longer I study the matter, the more am I inclined to believe that a healthy nerve in a healthy perineurilemma does not ache, or if it does so, the case is rare. Furthermore, the term "neuralgia" should 